\title{
Prognostic Factors in Patients with Multiple Myeloma
}

\author{
B. V. Afanasiev ${ }^{1}$, E. I. Podoltzeva ${ }^{2}$, E. V. Morozova ${ }^{1}$, V. A. Almazov ${ }^{2}$, \\ L. S. Zubarovskaya ${ }^{1}$, and V. M. Kravzova ${ }^{1}$
}

\section{Introduction}

Multiple myeloma (MM) is a malignant clonal B-lymphoproliferative disease. Survival ranges from a few months to many years [7]. The determination of prognosis for the disease's course is important in therapeutic choice. At least two factors determine the course of MM:

1) the biology of myeloma cells and

2) the interrelation of malignant cells and host organism.

That is why the morphology of myeloma cells is one of the most important prognostic factors of the disease [4]. There are also other prognostic factors associated with both malignant cell characteristics and the status of the host's immunocompetent system [7]. Taking into account the data on the decrease in colony-forming units - granulocyte/macrophage (CFU-GM) in MM $[2,11]$, and the antitumor effect of tumor necrosis factor alpha $(\mathrm{TNF} \alpha)$ [8, 9] and interleukin-2 (IL-2) [10], we investigated myeloma cell morphology, the level of serum $\beta_{2}$-microglobulin $\left(\mathrm{S} \beta_{2}-\mathrm{M}\right)$ and CFU-GM, TNF production by peripheral blood monocytes, and IL-2 production by peripheral blood mononuclear cells in different types of MM course in order to determine their prognostic significance.

1 Petrov Research Institute of Oncology, Leningrad, USSR.

2 The 1st Leningrad Medical Institute, Leningrad, USSR.

\section{Materials and Methods}

We investigated 101 patients with MM. Diagnosis was made according to previously described criteria [5].

Clinical Classification. It is impossible to predict individual prognosis in $\mathrm{MM}$ according to the stage of the disease [6] at the first presentation. That is why we classified our patients according to their life duration, which determined the type of the disease. This classification is a result of prospective investigation. We divided the patients into three groups: first - indolent myeloma, second - active myeloma, third - aggressive myeloma.

The diagnosis was made on the following criteria:

1) Indolent myeloma. Patients who presented with Kyle's criteria [7], patients who had been in remission for more than 5 years without chemotherapy, and patients with monoclonal gammopathy of undetermined significance who had been under investigation from 2 to 5 years (Fig. 1).

2) Active myeloma. Patients in whom first line chemotherapy was effective in achieving remission or the plateau stage. Median survival was 96 months.

3) Aggressive myeloma. Patients who had primary or secondary resistance to chemotherapy. Median Survival was 12 months.

Morphological Classification. The degree of myeloma cell maturation was determined according to the following criteria 


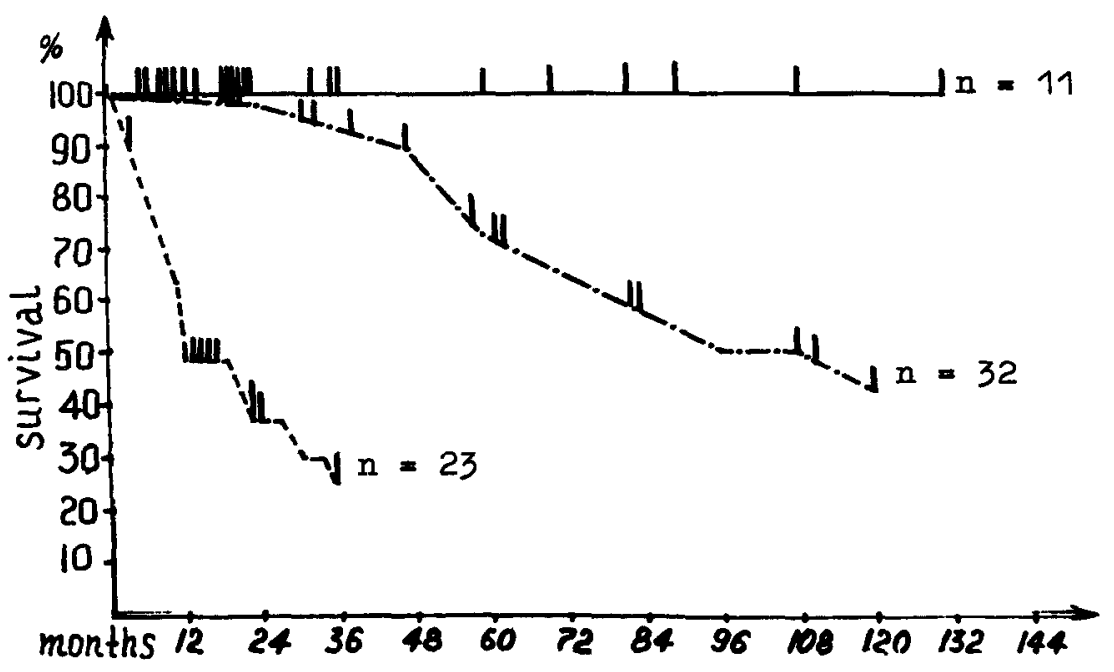

Fig. 1. Survival of patients with various courses of multiple myeloma. The solid line shows the indolent course; the dash-dot line, the active course, the line of dashes, the aggressive course of the morphological classification system for MM [4]:

1) mature - comprising more than $50 \%$ mature plasma cells;

2) immature - comprising more than $50 \%$ proplasmacytes and mixed cell myeloma where none of the morphologically distinct plasma cell types exceed $50 \%$ (the proportion of lymphoplasmacytoid cells was always less than $50 \%$ of the bone marrow plasma cells);

3) plasmablastic - comprising more than $50 \%$ plasmablasts.

Serum $\beta_{2}$-Microglobulin. $\mathrm{S} \beta_{2}-\mathrm{M}$ was measured by ${ }^{125}$ I radioimmunoassay.

Colony-Forming Unit-Granulocyte/Macrophage. The cloning of hemopoietic cells was performed in a agar drop-liquid medium system [1].

Biological Activity of IL-2. The biological activity of IL-2 in conditioned media of peripheral blood mononuclear cells was assayed according to the method reported by Bockman and Ropo [3].

$\mathbf{T N F}_{\alpha}$ Activity. The spontaneous and pyrogen-stimulated $(50 \mu \mathrm{l} / \mathrm{ml})$ production of $\mathrm{TNF}_{\alpha}$ by peripheral blood mono- cytes was assayed by exploring the immunoenzyme kits (performed by the Institute of High Purified Preparations (HPP) Leningrad, USSR), based on monoclonal and polyclonal antibodies to $\mathrm{TNF}_{\alpha}$. In order to form the calibration curve in each case $\mathrm{TNF}_{\alpha}$ was used (made by NPO "Ferment", Tallin, USSR).

\section{Results}

It was revealed that mature plasma cells were the morphological substrate in indolent myeloma (Fig. 2) at the same time in active myeloma, mature cells predominated in $77 \%$ of the patients, whereby in the remaining $23 \%$ of the patients, the cells were immature. In aggressive myeloma, immature cells were the main morphological type in $56.3 \%$ of the patients, plasmablasts prevailed in $37.5 \%$ of the patients, and mature cells were in $6.2 \%$ of the patients.

We discovered that the level of $\mathrm{S} \beta_{2}-\mathrm{M}$ correlated with the course of MM in most of the patients (Fig. 3). There was a significant difference between the level of $\mathrm{S} \beta_{2}-\mathrm{M}$ in patients with indolent myeloma $(3.3 \pm 0.4 \mathrm{mg} / \mathrm{l})$ and in healthy controls $(1.7 \pm 0.4 \mathrm{mg} / 1 ; p<0.05)$. We revealed a significant difference between the level of 


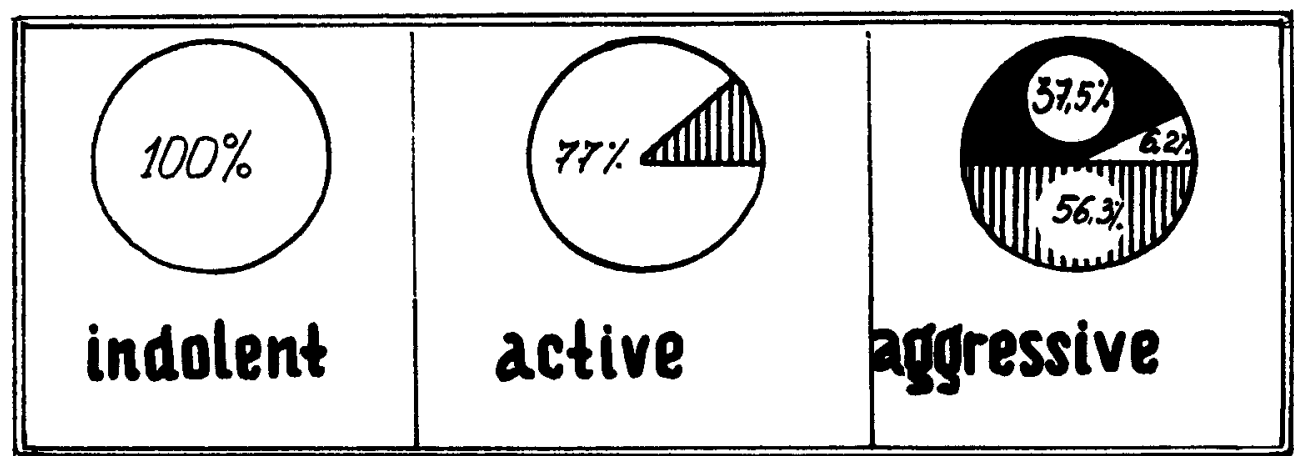

Fig. 2. Morphology and course of MM. The white area shows the percentage of mature

cells; the hatched area, the immature cells; and the black area, the plasmoblastic cells

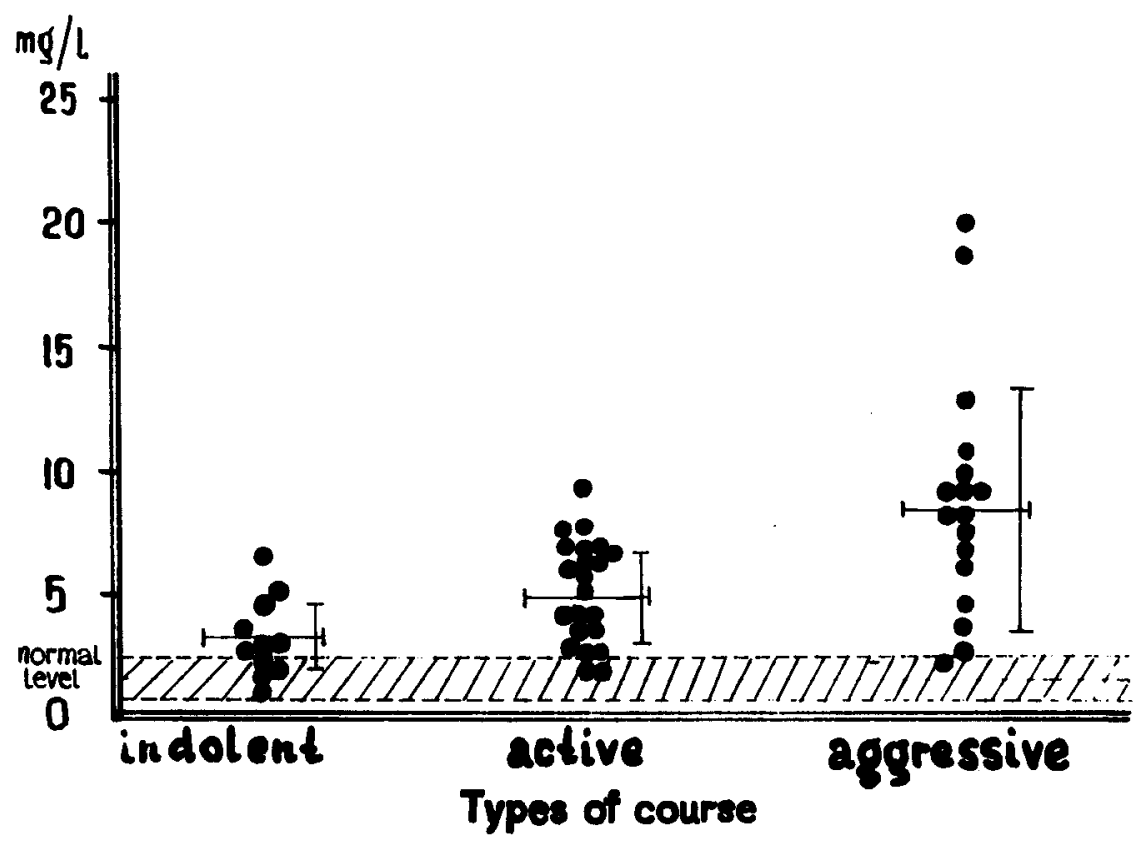

Fig. 3. Serum $\beta_{2}$-microglobulin and types of courses in patients with multiple myeloma

$\mathrm{S} \beta_{2}-\mathrm{M}$ in patients with indolent and active myeloma $(4.9 \pm 0.4 \mathrm{mg} / 1 ; p<0.05)$. There was also significant difference between the level of $\mathrm{S} \beta_{2}-\mathrm{M}$ in patients with active and aggressive myeloma $(8.6 \pm 1.2 \mathrm{mg} / \mathrm{l} ; p<0.05)$ and a significant difference between patients with aggressive and indolent courses $(p<0.01$; Fig. 4).

Studies on the clonogenic ability of CFU-GM in patients with an indolent course gave unusual results. In most patients with an indolent course, the number of CFU-GM was higher than in healthy controls (Fig. 5). The number of colony-forming cells in agar culture ranged from 30 to 300 per $10^{5}$ bone marrow cells, whereas in normal bone marrow cells it ranged from 40 to 60 per $10^{5}$ bone marrow cells. High levels of CFU-GM were also found in some patients with active myeloma as compared with healthy controls. The number of colony-forming cells in agar culture in active myeloma ranged from 42 to 420 per $10^{5}$ bone marrow cells. In patients with aggressive myeloma the number of colony-forming cells in agar culture ranged from 0 to 25 per $10^{5}$ bone marrow cells, which was much less than in patients with indolent and active myeloma and less than in normal controls.

There was an insignificant difference in IL-2 production between healthy con- 


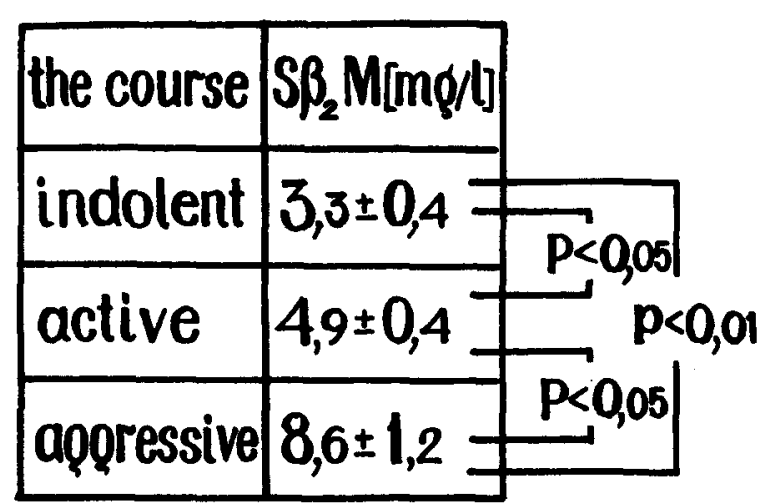

Fig. 4. Serum $\beta_{2}$-microglobulin and the course of multiple myeloma

trols $(13.9 \pm 1.2$ units of activity; $p<0.05)$ and patients with indolent $(12.9 \pm 1.1$ units of activity) (Figs. 6, 7) and active courses (11.9 \pm 0.7 units of activity) and between the indolent and active courses. Then significant differences were found in the IL-2 production between patients with active and aggressive myeloma $(8.6 \pm 0.6$ units of activity; $p<0.01)$ and also between aggressive and indolent myeloma and healthy controls $(p<0.01)$.

An insignificant difference between the pyrogen-stimulated production of $\mathrm{TNF}_{\alpha}$ in patients with an indolent course $(1.5 \pm 0.3 \mathrm{ng} / \mathrm{ml})$ and healthy controls $(2.2 \pm 0.38 \mathrm{ng} / \mathrm{ml})$ was detected $(p>0.05$; Fig. 8).

A significant difference was found between the pyrogen-stimulated production of $\mathrm{TNF}_{\alpha}$ in patients with indolent and active courses $(6.1 \pm 1.1 \mathrm{ng} / \mathrm{ml}$; $p<0.01)$. There was also a significant different in $\mathrm{TNF}_{\alpha}$ production between patients with active myeloma and healthy controls $(p<0.05)$, and also in $\mathrm{TNF}_{\alpha}$ production in patients with active and aggressive myeloma $(2.0 \pm 1.2 \mathrm{ng} / \mathrm{ml}$; $p<0.05$ ). There was an insignificant difference between $\mathrm{TNF}_{\alpha}$ production in patients with aggressive and indolent courses and healthy controls $(p>0.05$; Fig. 9).

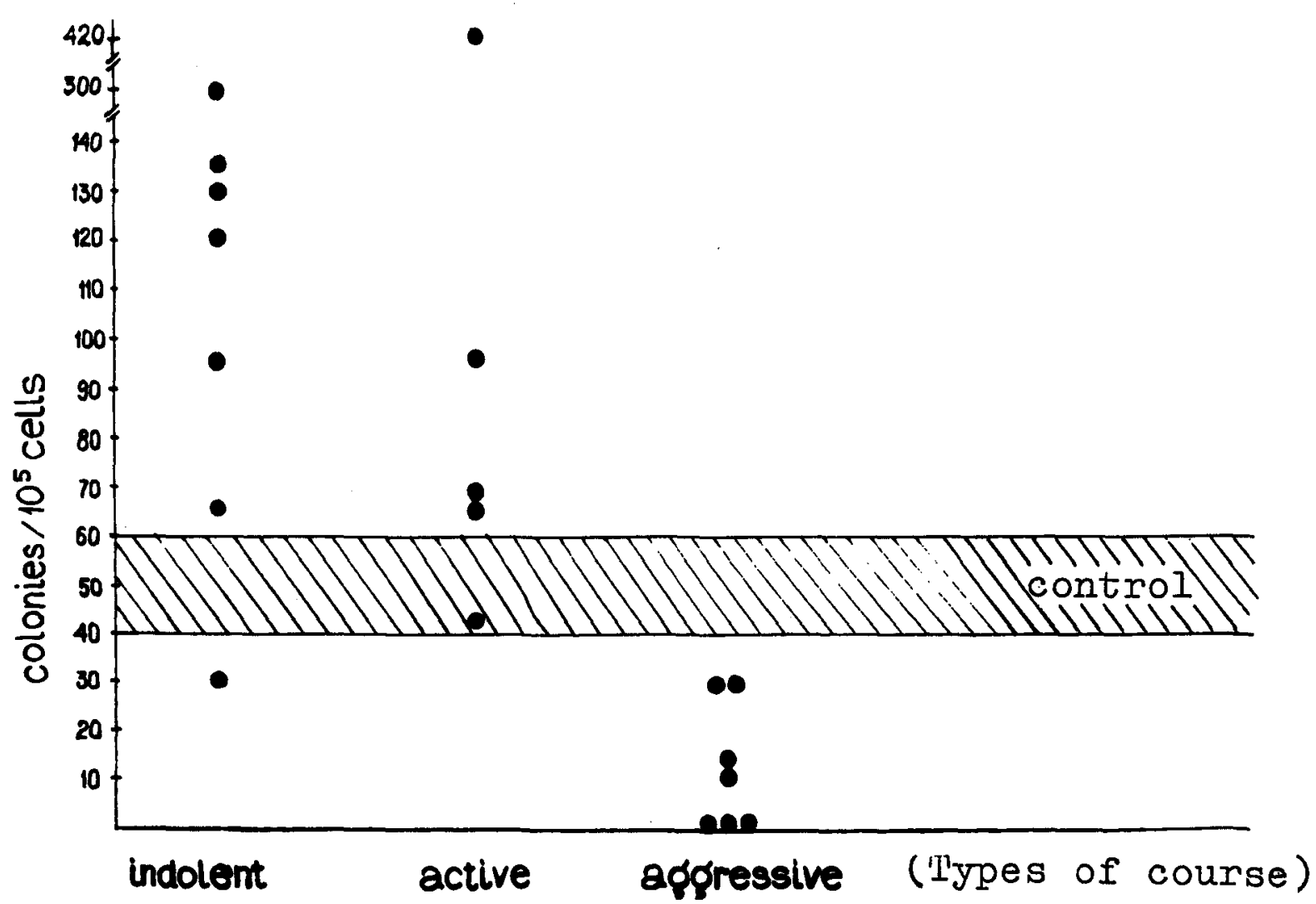

Fig. 5. Colony-forming unit granulocyte and macrophage of bone marrow and the multiple myeloma course 


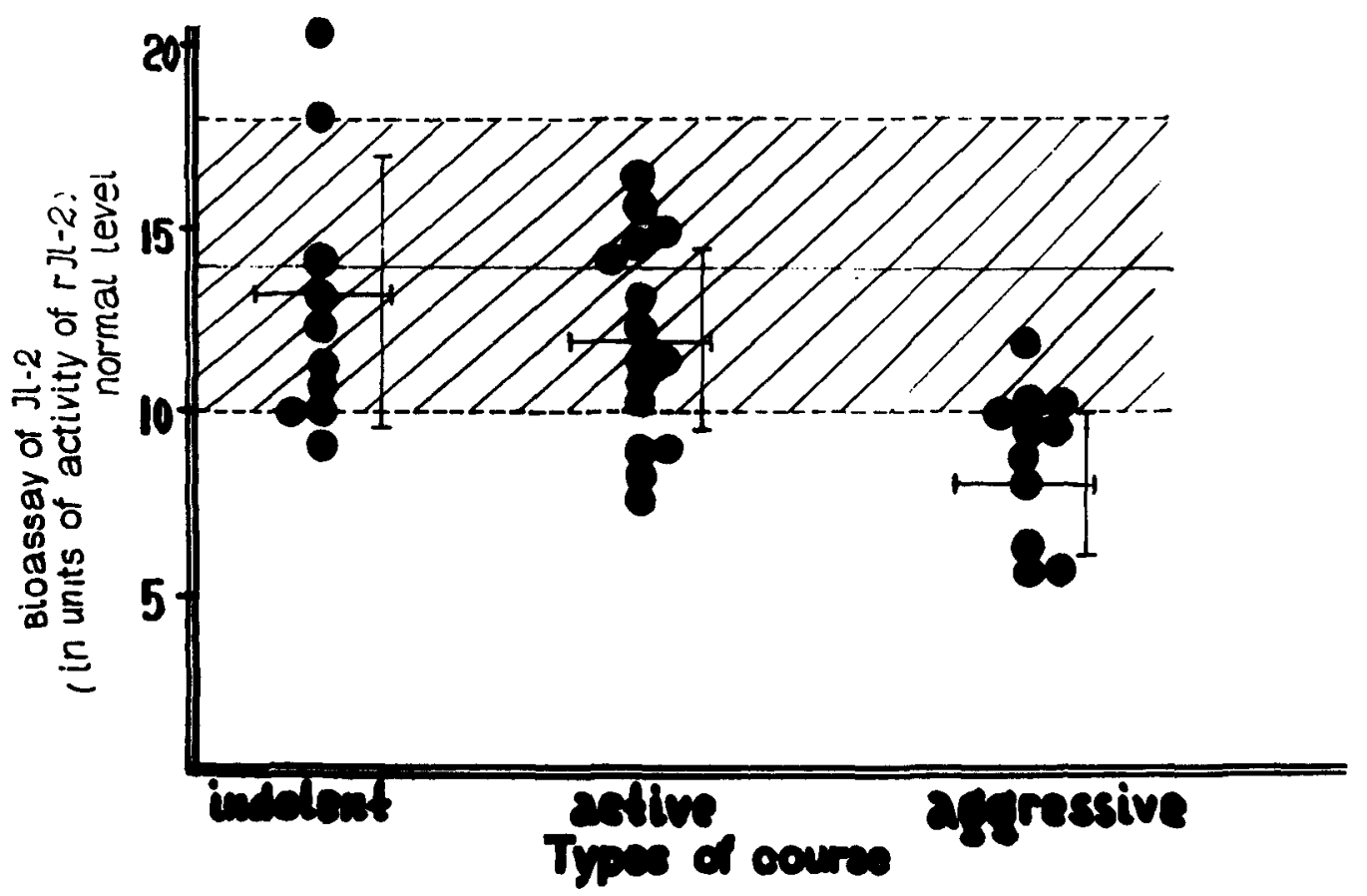

Fig. 6. Production of interleukin-2 by peripheral blood mononuclear cells in patients

with different types of courses in multiple myeloma

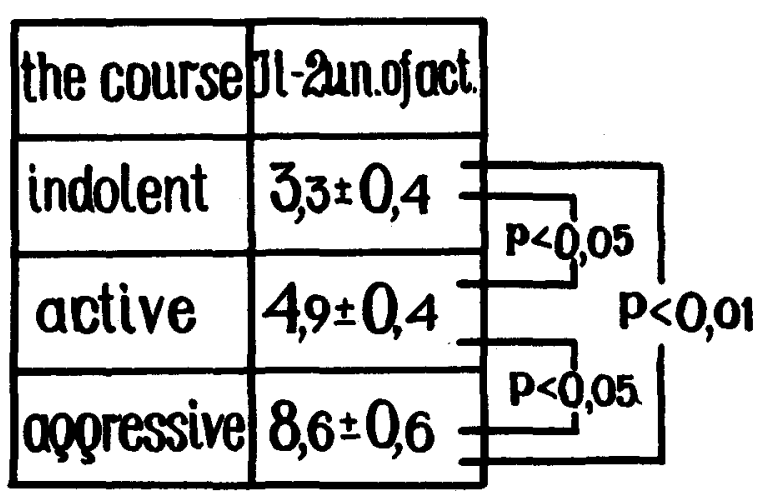

Fig. 7. Interieukin-2 and the course of multiple myeloma

\section{Conclusion}

Our data suggest that:

1) Morphology of myeloma cells is the most important prognostic factor which, without a doubt, can be easily reproduced, and is widely used in clinical practice.

2) The level of $S \beta_{2}-M$ may be used to determine the MM course type.

3) CFU-GM probably may also be used as a prognostic factor. An increased or normal level of CFU-GM confirms the indolent or active course of MM, while a decreased level of CFU-GM reflects the aggression of MM.

4) Decreased production of IL-2 by peripheral blood monocytes is characteristic of an aggressive MM course.

5) $\mathrm{TNF}_{\alpha}$ has a prognostic significance if it is used together with myeloma cell morphology as

a) mature myeloma cells and normal production of $\mathrm{TNF}_{\alpha}$ by peripheral blood monocytes are typical of an indolent course;

b) mature or immature morphology of myeloma cells and increased production of $\mathrm{TNF}_{\alpha}$ are typical of an active course; and

c) immature or plasmablastic morphology and normal production of $\mathrm{TNF}_{\alpha}$ are typical of an aggressive course.

The studies mentioned above were necessary in order to find out the role of these factors in MM pathogenesis. 


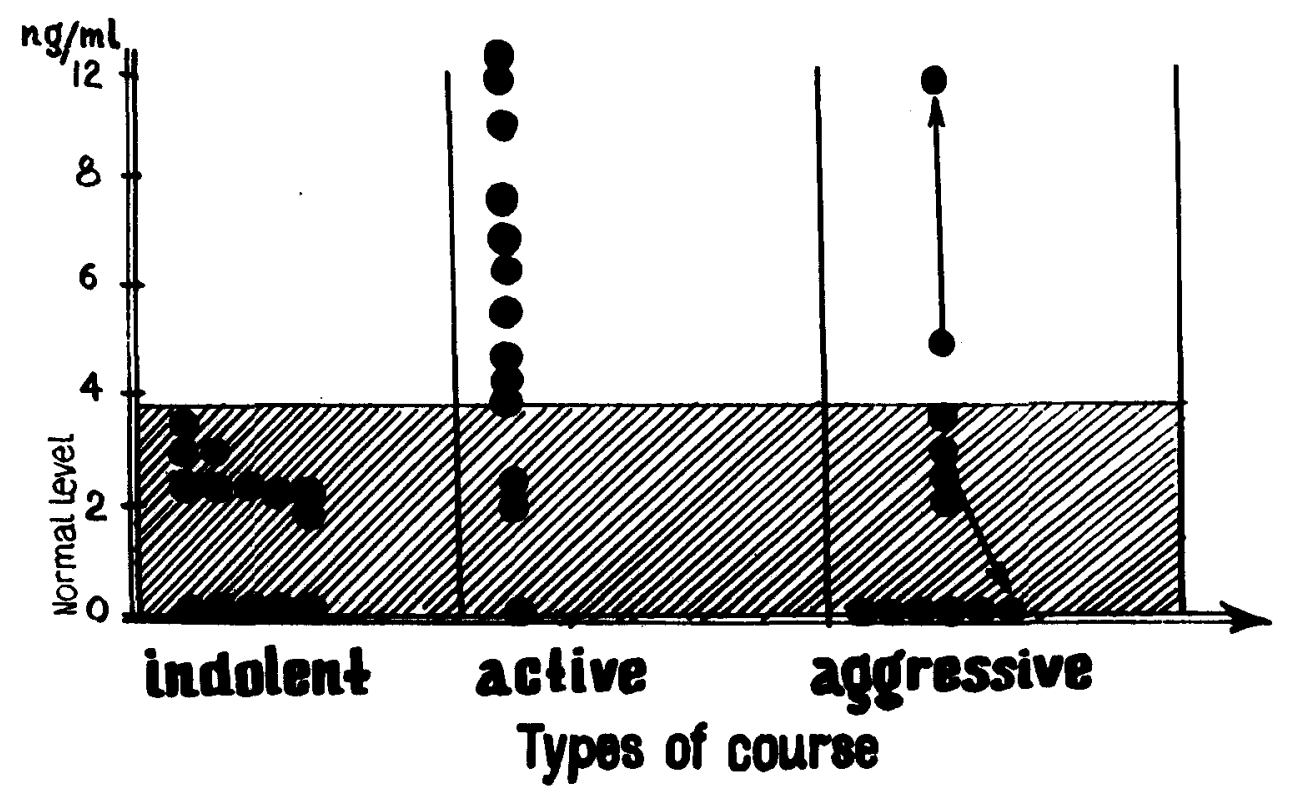

Fig. 8. Pyrogenal-stimulated tumor necrosis factor-alpha production by peripheral blood monocytes in patients with multiple myeloma

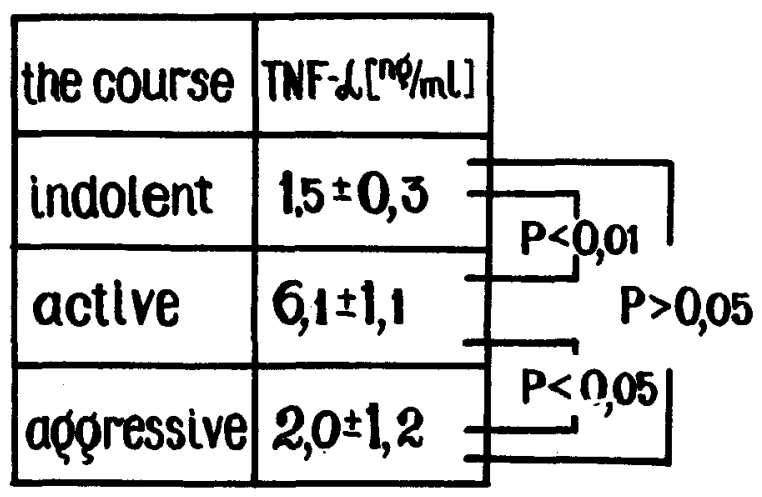

Fig. 9. Tumor necrosis factor-alpha and the course of multiple myeloma

\section{References}

1. Afanasiev BV, Tiranova SA, Kulibaba TG, Zubarovskaya LS, Bolshakova GD, Zabelina TS (1983) Cloning of human hemopoietic cells in the "agar drop-liquid medium" system. Ter Arkh 8:114

2. Almazov VA, Afanasiev BV, Zaritsky A, Chichkov A (1981) Leukopenia, Leningrad, "Medicine"

3. Bockman RS, Ropo MA (1981) Lymphokinemediated bone resorption requires endogenous prostaglandin synthesis. J Exp Med 154:529-534

4. Carter A, Hocherman J, Linn S, Cohen J, Tatarsky J (1987) Prognostic significance of plasma cell morphology in multiple myeloma. Cancer 60:1060-1065
5. Chronic Leukaemia-Myeloma Task Force of the National Cancer Institute (1968) Guidelines for protocol studies. II. Plasma cells myeloma. Cancer Chemother Rep $1: 17$

6. Durie BGM, Salmon SE (1975) A clinical staging system for multiple myeloma: correlation of measured myeloma cell mass with presenting clinical features, response to treatment, and survival. Cancer 36:842

7. Kyle RA (1988) Prognostic factor in multiple myeloma. Hematol Oncol 6:125-130

8. Palladino MA Jr, Shalaby MF, Kramer SM, et al. (1987) Characterization of the antitumor activities of human tumor necrosis factor- $\alpha$ and the comparison with other cytokines: induction of tumor specific immunity. J Immunol 138:4023

9. Price G, Brenner MK, Prentice HG, Newlands AJ (1987) Cytotoxic effects of tumour necrosis factor and gamma interferon on myeloid leukaemia blast cells. $\mathrm{Br}$ J Cancer 55:287

10. Rosenberg SA, Lotze MT, Muul LM, et al. (1987) A progress report on the treatment of 157 patients with advanced cancer using lymphokine-activated killer cells and interleukin-2 or high-dose interleukin-2 alone. N Engl J Med 316:889-897

11. Takahashi T, Lim B, Jamal N, Tritchler D, Lochwood G, McKinney S, Bergsagel DE, Messner HA (1985) Colony growth and self renewal of plasma cell precursora in multiple myeloma. J Clin Oncol 3:16131623 